\title{
The Metamorphosis of People Living with Human Immunodeficiency Virus (HIV)
}

\author{
Marie Lauren Michelle A. Hortillas \\ Lisa Anna M. Gayoles \\ University of Negros Occidental - Recoletos \\ lisagayoles@yahoo.com
}

\begin{abstract}
The present study aimed to investigate the lived experiences of being HIV positive; to describe common themes of experiences of being HIV positive; and to analyze the meaning of experiences of being HIV positive. The participants of this study were five HIV-positive men under the care of the Department of Health (DOH) Region VI in Iloilo City. Specifically, they belonged to the United Western Visayas Incorporated (UWVI), a community-based group of people living with HIV (PLHIV) based in Iloilo and operating in Panay and Guimaras areas. Narrative writing encouraged the participants to rummage through emotions tied to being HIV positive. This gave them the chance to revisit strong feelings without divulging their identities, thus protecting their anonymity. Eight main textural themes emerged from the lived experiences of these men, namely: disclosure of HIV-positive status; stigma and discrimination attached to HIV; social support from family, friends, and others; depression accompanying the diagnosis; the physical symptoms experienced during seroconversion; antiretroviral therapy after the diagnosis; and HIV advocacy with UWVI. These HIV positive men have metamorphosed, from the acceptance of their HIV positive status to reinventing their new reality and finding purpose through their HIV advocacy. The findings suggest implications for supportive counseling to provide empathy, support and encouragement, and developing specific coping strategies with PLHIV.
\end{abstract}

Keywords: HIV Positive, Lived Experiences, Disclosure, Stigma and Discrimination, Social Support, Depression, Physical Symptoms, Antiretroviral Therapy, HIV Advocacy

Date Submitted: November 30, 2018

Date Revised: February 2, 2019 


\subsection{Introduction}

During the Miss Universe pageant on December 20, 2015 in Las Vegas, Nevada, USA, Miss Philippines Pia Alonzo Wurtzbach, as one of the final three, was asked "Why should you be the next Miss Universe?" She answered, "...I would (sic) raise awareness to certain causes like HIV awareness that is timely and relevant to my country which is the Philippines..." (Vila, 2015).

HIV awareness is a step toward acknowledging and addressing the needs of people in response to the HIV/AIDS pandemic. Human Immunodeficiency Virus/ Acquired Immune Deficiency Syndrome (HIV/AIDS) shares a place in the list of pandemics throughout history, together with plague, typhus, cholera, and influenza. It is currently second to typhus, which is caused by bacteria that are spread to humans by fleas and lice, which last for 87 years (Nordqvist, 2014).

In the November 2015 report of the Epidemiology Bureau of the Department of Health (DOH), the highest reported cases since 1984 was in June 2015, with 772 new cases (Philippine HIV Registry, 2015). According to CNN Philippines, as of December 2015, health officials have recorded 650 HIV cases. The DOH recorded 461 reported deaths of HIV cases last year (Tordecilla, 2016).

Despite various campaigns to educate people about HIV/AIDS, many myths such as HIV transmitted through insect bites, toilet seats, kissing, touching, mutual masturbation, oral sex, and used condoms (CDC, 2015), and stigmas such as HIV/AIDS connected to men having sex with other men (MSM), drug use, and moral weakness that deserve punishment, continue to exist. Many HIV positive people hide their HIV status from family, friends, and employers due to the fear of rejection and are forced to carry the burden silently. Thus, HIV positive people do not always receive the social support that research has shown to be of great value, and this may lead to a life of isolation, depression, and loneliness (Roldán, 2007).

In order to combat stigma and discrimination connected with HIV/AIDS, there is a need to eradicate fear and misunderstanding. Perhaps one way of doing this is to allow HIV positive people living in lloilo City to express themselves by sharing their stories of their experiences of living with HIV. Hopefully by doing so, other HIV positive Ilonggos may realize that they are not alone and may find the courage to disclose their situation. For llonggos without HIV, reading stories of fellow llonggos inflicted with the disease will provide insights and understanding, thus removing some of the myths and the stigma attached to it.

The present study deals with community health psychology, which is concerned with the theory and method of working with communities to combat disease and to promote health (Murray, Nelson, Poland, Maticka-Tyndale \& Ferris, 2004). This field is of interest to the researcher as a Quality Management Staff member at a medical and diagnostic center in Iloilo City that engages in various aspects of health care delivery, committed in meeting the requirements of its clients' principals for mentally, physically and dentally fit Filipino crew and workers. This medical and diagnostic center is required to perform HIV testing to all seafarers and overseas Filipino workers (OFWs). It is also required to perform HIV counseling to clients that are HIV/AIDS positive. This study will help the different maritime industries and their affiliated health centers to promote 
awareness regarding HIV/AIDS, to develop programs to aid in risk reduction behavior, and to provide support to seafarers and OFWs, including their families.

The purpose of this study was to explore, describe, and interpret the experiences of HIV positive men in Iloilo City. An HIV positive status is linked to problems for the infected and as well as the uninfected. In order to address issues of stigma and discrimination, anxiety, and depression, it is necessary to study the experiences of these HIV positive men.

The study aimed to meet the following objectives: to investigate the lived experiences of being HIV positive, to describe common themes of experiences of being HIV positive, and to analyze the meaning of experiences of being HIV positive.

\subsection{Theoretical Considerations}

Phenomenology refers to a set of philosophical doctrines loosely sharing assumptions as to what the world is like (ontological) and how it can be known (epistemological) and strategies for the descriptive management of the mental entities relating to such a world. They all strive to capture experiential essences (Kafle, 2011). Ontology is concerned with reality. Reality is perceived as a construct dependent on different situations. Epistemology is concerned with "how we know and what we know." Epistemology is anchored on the belief that knowledge making is possible through subjective experiences and insights. According to Christensen, Johnson, and Turner, the primary objective of a phenomenological study is to explicate the meaning, structure, and essence of the lived experiences of a person, or a group of people, around a specific phenomenon (Simon \& Goes, 2013). The researcher attempted to understand human behavior through the eyes of the participants in the study by providing a rich textured description of lived experience.

This study is anchored on the coping theories of Lazarus and Folkman According to Lazarus and Folkman, coping is the sum of cognitive and behavioral efforts, which are constantly changing, that aim to handle particular demands. Coping is an activity, which is done to seek and apply solutions to stressful situations or problems that emerge because of the stressors (Pandey \& Kulkarni, 2015).

Each individual experiences a positive test result for HIV uniquely; nevertheless, there are common reactions and emotions expressed after the diagnosis. Their initial shock is followed by denial, fear, anger, guilt, self-blame, and self-shame.

Once a diagnosis is made, a major decision to be made involves disclosure of the HIV status. The HIV-infected may start with no disclosure or limited disclosure. Disclosure is an ongoing process and not just an issue at the time of diagnosis. Unfortunately, stigma and discrimination are the greatest barriers for disclosure, which translate to HIV-infected individuals unable to avail of proper care and treatment.

Aside from these social issues HIV positive people have to deal with, there are psychological issues as well. The grieving process starts as soon as a diagnosis is made. These individuals, together with their family and friends, are likely to experience anticipatory, acute, and/or chronic grief. They may also experience anxiety, insomnia, and depression. 
The results of the study conducted by Rouleau, Cote and Cara (2012) indicated feelings of ambivalence, expressing the gratitude of the care extended as well as the continued stigma and discrimination that go with disclosure.

The outcomes of the study of Mohammadpour, Yekta, Nasrabadi, Ahmadi, and Mohammad Zadeh (2014) revealed that one of the themes of HIV-infected individuals is hope and fear. These individuals experience fear, doubts, and worries, along with hope.

Rodkjaer, Sodemann, Ostergaard, and Lomborg (2011) applied the concept of self-efficacy in coping with living with HIV/AIDS to determine its impact on depressive symptoms of HIV-infected patients. They uncovered that disclosure of their HIV status is a social stressor, and low coping self-efficacy contributes to nondisclosure of HIV status and depression. Likewise, Yeji, Klipstein-Grobusch, Newell, Hirschhorn, Hosegood, and Bärnighausen, (2014) investigated whether depression among HIV-infected adults receiving antiretroviral treatment (ART) is associated with social support and HIV coping strategies. Their findings indicated that instrumental social support was associated with lower incidence of depression while avoidance of people increased the incidence of depression. Furthermore, Mahmoudi, Dehdari, Shojaeezadeh \& Abbasian (2015) conducted a study to explain how stress adversely impacts on health outcomes of HIVinfected patients. They explored coping with stress strategies by HIV positive individuals and found that both emotion-based coping and problem-based coping were utilized.

The findings of the investigation conducted by McQuillen (2014) revealed three themes and one theory of generativity gathered from aging people with HIV/ AIDS. The three themes were choices and decisions; information and understanding; and purpose; and the theory was McAdams' theory of generativity which focused on making sense and finding meaning to their lives.

The study conducted by Canoy and Ofreneo (2011) on the subjective experience of young Filipino gay men living with HIV in their first year of diagnosis revealed common themes focused on the young gay men's experiences of HIV testing and the process of othering in the workplace; experiences of emotional struggles and the process of disclosure in the family; and experiences coming to terms with their HIV status and the process of reconstructing the self.

\subsection{Methodology}

This paper presents a qualitative design, specifically a phenomenological study. Phenomenology has been conceptualized as a philosophy, a research method, and an overarching perspective from which all qualitative research is sourced (Kafle, 2011).

The most common method of data collection in a phenomenological study is through in-depth interviews to gather the participants' detailed descriptions of their experiences. However, participants' written or oral self-reports, or even their aesthetic expressions, for example, art, narratives, or poetry, can also be evaluated (Simon \& Goes, 2013). Through the use of written narrative stories and documentation, the goal is to gain knowledge and understanding of being HIV positive.

Narrative writing can provide a therapeutic outlet for the participants, allowing them to relive an event and gain clarity and peace. Narrative writing encourages an HIV positive individual to delve into the specific emotions tied to being HIV positive, giving him/her a chance to revisit strong feelings without divulging himself/herself 
through a face-to-face contact for the protection of anonymity (Tuffelmire, 2015). Since phenomenology focuses on how people make sense of their experiences and the world, how they develop a worldview, and how to make sense of experience and transform experience into consciousness (Sailor, 2013), the researcher conducted this study with individuals who have lived experiences of HIV infection and provided a better understanding of the psychosocial effects of being HIV positive.

The participants of this study were five HIV positive men under the care of the Department of Health (DOH) Region VI in lloilo City. Specifically, they belong to the United Western Visayas Incorporated, a community-based group of people living with HIV based in Iloilo and operating in Panay and Guimaras areas.

The sampling technique in this study is non-probability purposive sampling where the selection of the participants meets the purpose of the study (Kafle, 2011; Ardales, 2008; Starks \& Trinidad, 2007; Groenwald, 2004). Snowball sampling was utilized to recruit for additional participants. It is a method of expanding the sample size by asking one participant to recommend others for the study (Groenewald, 2004).

The validity of this study was verified concurrently with the data explication (Simon \& Goes, 2013). Specific procedures were taken to address credibility, fittingness, and auditability. The credibility of the researchers' interpretations of the data was verified by the participants. Fittingness or transferability of the study refers to the probability that the research findings have meaning to others in similar situations.

Data were interpreted and transformed through data explication by the researcher. This explication process involved bracketing and phenomenological reduction; delineating units of meaning; clustering of units of meaning to form themes; summarizing each written narrative story, validating it and when necessary modifying it; and extracting general and unique themes from all the interviews and making a composite summary (Groenewald, 2004).

To ensure ethical research, the researcher prepared an informed consent form. Honesty together with confidentiality reduces suspicion and promotes sincere responses (Groenewald, 2004). The informed consent form was explained to the participants at the distribution of writing materials for the written narrative stories.

\subsection{Results}

The purpose of this study was to explore, describe, and interpret the lived experiences of HIV positive males, members of the United Western Visayas, Incorporated (UWVI), a community-based group of people living with HIV (PLHIV). Main textural themes were found in three or more of the written narrative stories. These themes were: disclosure, stigma and discrimination, social support, depression, physical symptoms, antiretroviral therapy, and HIV advocacy.

Disclosure. Once a diagnosis is made, the person is faced with the decision for disclosure of his or her HIV serostatus. Almost all the participants disclosed to at least one person, most often a family member.

"I called out for help. And somehow I got it." "With my family, my mother was the most affected." "I also started to disclose my status with friends whom I know I 
can trust..." "After the mass I asked mom to stay, sabi ko 'ma can we stay? May sasabihin lang ako'." (I said, "Ma, can we stay? I have something to tell you.") "Walang ani e napayakap ako sa uncle ko at napaiyak, humagulhol at pauli ulit na nagsasabi ng 'Sorry'." (Without much ado, I embraced my uncle and cried so loud, continuously saying "Sorry".)

Stigma and discrimination. Stigma influenced the decision to disclose HIV status, fearing being discriminated against because of their HIV-positive status. "\#Stigma is the killer." The participants experienced discrimination from their own family.

"I also experienced being stigmatized and discriminated; other people love to send messages like I was in the hospital and being isolated because I have HIV." "My family still treats me the same although at first I felt some discrimination like; I have my own eating utensils, own glass, own bathroom (if that was possible)." "When my relatives knew that I tested positive they were afraid that I might pass the infection to their children, so they decided to transfer me to an apartment. I stayed there for 2months alone." "The first person who stigmatized and discriminated me were my own parents along with some of my relatives. It was like every day that I woke up everything just keeps getting worse." "After the event umuwi ako sa amin at napansin ko na may kakaiba na sa mga kinikilos ng mama ko, nagpunta ako sa house ng pinsan ko na nurse ganun din na parang kakaiba ang mga approach na nakakapanibago." (After the event I went home to our house and I noticed that my mama's behavior was different. I went to the house of my cousin who is a nurse and I noticed the changes in their approach which I found quiet disturbing.)

"Tumagal daw ng 4 hours ang paguusap nila, iyakan, nagbitiw ng di magandang salita tungkol sakin." (They talked for almost four hours; there were crying and derogatory statements about me that were made.)

Social support. Again, stigma influenced the participants' decision to seek for social support.

"Pwede din itong mapagmahal na kapatid sa malayo ... o maasahang pinsan na kasama sa bahay at karamay sa luha at galak ng buhay o mga magulang na hindi man maintindihan kung ano ang sakit mo pero ang alam lang nila ay intindihin ka at mahalin ka... Mga kamag-anak at kapitbahay na tutulungan ka magbuhat ng iyong mabigat na dalahin. Mga kaibigang tinanggap ka at pilit ka pinapangiti at pinapatawa... Or it could be complete strangers..." (It can be the love of a sibling far away... or a trusted cousin who stays with you at home through the laughter and the tears of life. Or parents who, even if they don't fully understand your illness, will understand and love you... or relatives and neighbors who will help carry the burden. And friends who accept you and force you to smile and laugh... Or it could be complete strangers...)

"... my dad was very understanding and he knew that there was no place for sermons and so he just kept quiet. Even though I haven't heard a thing from him, still he showed compassion and love for me since he was the only one who accompanied me during weekends at my apartment." 
Depression. The participants manifested depression with feelings of worthlessness and hopelessness, suicide ideation, and fear of living with and dying from HIV.

"... tested and got the positive and reactive result. I sometimes cannot stop myself to feel sorry. In my mind I told myself I should have done more..." "It is very hard and the pain is incomparable." "When I was diagnosed, all came to a complete halt. I was overshadowed by complete darkness, and I don't know where to start again with my life or what is left of it. I cried buckets of tears thinking that I was totally useless." "I cried, I blamed myself and even wanted to commit suicide."

One participant expressed that through social support, his psychological wellbeing improved. "Depression is normal but what is important is we have someone whom we can hang on to, to share how/what we feel and to just vent out all the emotions that we keep and store for a long time."

Physical symptoms. Because of the appearance of physical symptoms associated with HIV/AIDS, the participants were eventually diagnosed with HIV.

"I already suffered from on and off flu, tonsillitis and sore throat. I suffered from Herpes Zoster... in that early stage already of HIV." "Before I was diagnosed, some of friends already noticed and told me that I seemed losing weight... I already felt and suffered from on and off fever symptoms." "I suffered from different opportunistic infections like T.B, pneumonia, anemia, rashes, amoebiasis, Hepa A." "... my CD4 dropped to 107..." "Prior to the test I had Sexually Transmitted Infection." "... wala na kong ganang kumain at minsan inaatake ako ng init ng katawan..." (... I lost my appetite and sometimes I have a fever...)

These physical symptoms triggered their initial diagnoses. Consequently, these triggers influenced decision making with regard disclosing their HIV status, starting treatment, and continuing intimate relationships.

Antiretroviral therapy (ART). Antiretrovirals are drugs used to treat HIV. For these participants, ART and a healthy lifestyle helped them cope with the seriousness of HIV, giving them a reason and a purpose to strive for survival.

"I discovered what this HAART will do to the virus." "ARV drugs will stop the virus from reproducing... and if you are adherent to your medicine schedule, ARV will hold them up there, forever..." "Treatment is available and it helps prolong your life, along with healthy lifestyle, frequent visit with your doctor and positive outlook, you can live a normal life and would even live with a longer life expectancy." "Sa loob po ng isang taon bago ako nagdisclose sa family ko inalagaan ko po sarili ko, kumain ng tama at umiinom ng ARV sa tamang oras, I seldom eat junks na and synthetic food and drinks kaya hindi ako nahalata ng tao at ng family ko na may sakit ako." (In one year before I disclosed to my family I took good care of myself, I ate right and drank my ARV on time, I seldom eat junks and synthetic food and drinks that people and even my family didn't notice that I am sick.) 
HIV advocacy. All participants are HIV advocates, all being members of the United Western Visayas Incorporated (UWVI). For the participants, it was important to find purpose in life in spite of their HIV positive status.

"Now I am a full advocate and HIV counsellor in an organization." "I became active to the point that I have already become an advocate and HIV councilor of HIV and AIDS." "I am empowered, I am positive; I know I can be better to save lives." "Living with HIV and has inspired me to push through with my Advocacy." "I finally get it now. I am not only doing this for myself or for my fellow PLHIV's but I'm doing this for everyone." "Sa ngayon po I'm active in HIV advocacy as a Peer Educator and a Certified Trainer." (I'm now active in HIV advocacy as a Peer Educator and a Certified Trainer.) "Sa ngayon isa akong advocate patungkol sa HIV/AIDS una concern at namamasukan bilang isang ADMIN Clerk and also HIV/ AIDS COUNSELOR." (I am now an advocate for HIV/AIDS originally out of concern and now work as an administrative clerk and also an HIV/AIDS counselor.)

What is the essence of the lived experiences of these HIV positive men? Living with HIV is akin to metamorphosis, the process of transforming an immature form to an adult form in different stages. A mature female butterfly or moth lays the eggs. These eggs hatch into worm-like creatures, the caterpillar. These caterpillars' voracious appetite can be very destructive to crops. The next stage of the butterfly or moth metamorphosis is the pupa. The pupae of silk moths are the source of silk, a soft, lustrous fiber. Thus, the destructive nature of these caterpillars gives rise to one of the finest cloths in the world. And finally, the butterfly emerges from the pupa, in all its splendid colors.

The presence of HIV in the body, when left untreated, can just be as destructive. An HIV diagnosis is no longer a death sentence, but rather a long-term condition. For these HIV positive men, living with HIV has made them accept their condition and learn to move beyond their crises. Positive change for these men starts by accepting who they are and by allowing those around them to accept them as well.

\subsection{Discussion}

Disclosure: to reveal or not to reveal. This is the dilemma every individual diagnosed with HIV has to decide on. Disclosure also involves whom to disclose the serostatus to (Rodkjaer et al., 2011). "Do I become open, partly open, or close?" Disclosure may help by sharing the burden of the diagnosis as it provides some support for the HIV-infected person; however, it may also be negative because of stigma and discrimination (Hall, 2003). This decision also includes whom to disclose the serostatus to. Disclosure is made to at least one person, usually a family member (Hall, 2003).

Stigma and discrimination: label jars not people. Stigma influences the decision to disclose HIV status due to shame and fear of being discriminated against because of an HIV positive status. Stigma created negative beliefs and feelings within the participants, which is linked to the external stigma in the form of discrimination from their own family (Crowley \& Guni, 2004). This internalized stigma can have a profound effect on their treatment and care. Participants reported both felt stigma, which PLHIV 
perceive to exist, as well as enacted stigma, which PLHIV actually experience (Hall, 2003).

Social support: compassion through action. Social support can improve coping skills of PLHIV (Pandey \& Kulkarni, 2015). It may be the only source of care for some PLHIV. Social support from family and friends or even complete strangers is essential for the well-being of the participants.

Depression: In the darkness cast by HIV, participants reported their lives changed with the diagnosis of HIV. Depression is a mental disorder which is associated with depressed mood characterized by sadness, emptiness, or hopelessness; markedly diminished interest or pleasure in all or almost all activities; feelings of worthlessness or excessive or inappropriate guilt; or recurrent suicidal ideation or a specific plan for committing suicide with significant distress or impairment in social, occupational, or other important areas of functioning (American Psychiatric Association, 2013; HIV Clinical Resource, 2013). In PLHIV, it is represented by feelings of worthlessness and hopelessness, suicide ideation, and fear of living with and dying from HIV (Hall, 2003). Depression appears to be included in PLHIV's experiences (HIV Clinical Resource, 2013). The participants expressed their depression in different ways and recognized it. It is unfortunate that the depression of some PLHIV is unrecognized.

Physical symptoms: telltale signs of HIV. Physical symptoms are associated with the diagnosis of HIV. Physical symptoms can be considered as a coping style that helps the HIV infected to focus on what is happening to his or her body and eventually adopt a healthy lifestyle (Hall, 2003). Through the recognition of their symptoms, the majority of the participants sought medical assistance and ultimately found out about their diagnosis. This influenced their decision making with regard to disclosure, treatment, and having or intimate relationships. It is important to remember that some physical symptoms may be due to depression brought about by the diagnosis (HIV Clinical Resource, 2010).

Antiretroviral therapy: the ART of HIV. There is no cure for HIV. ART controls the virus, which gives the participants a hope for survival (HIV Positive Magazine, 2015; Hall, 2003). Most PLHIV's consider medication as a means of hope to continue living a normal life or as a means to prevent disclosing their HIV positive status (Hall, 2003). All participants have been receiving ART through DOH Region VI. They realized that ART is imperative for them to survive longer. None of them utilized complementary and alternative medicine (AIDS.gov, 2015a), which is used in adjunct to the conventional medicine.

HIV advocacy: empowering PLHIV. HIV advocacy comes in many forms such as focusing on policies and programs in response to the HIV epidemic, providing information, providing treatment access, case management, supportive counseling, and advocating for services for specific groups, and searching for a cure for HIV/AIDS (ACOG, 2016). The UWVI is a support group which provides the participants the opportunity 
to interact with other PLHIV's and provides a corrective model to explore and identify their own personal beliefs that empowered them and gave them their purpose in life. UWVI advocates the prevention of HIV and the promotion of treatment and care among its members as well as affected families. It addresses the stigma and discrimination attached to HIV/AIDS in order to build the confidence of newly diagnosed individuals to access services at the local treatment hub at the Western Visayas Medical Center, Iloilo City.

The metamorphosis of HIV positive men. The presence of HIV in the body when untreated is destructive. An HIV diagnosis is no longer a death sentence, but rather a long-term condition. For these HIV positive men, living with HIV has made them accept their condition and learn to move beyond their crises. They have metamorphosed, from the acceptance of their HIV positive status to reinventing their new reality and finding purpose through their HIV advocacy. These men give renewed hope and joy to other PLHIV's.

\subsection{Conclusion}

For these men living with HIV, the diagnosis of HIV sets a chain of life-changing decisions. A diagnosis is like a specter of despair looming over. They had the task of making sense of it all. Despite the turmoil in their lives, they found the hope and the courage to live on.

PLHIV's should live life as normal as they can. They should adhere to their medication schedule and adopt a healthy lifestyle. It is important that family members, caregivers, and support groups give the emotional support PLHIV's need, want, and deserve. They should be open in addressing sensitive issues for successful prevention, care and support. Eventually, they become the source of strength of PLHIV's and help in reducing the stigma and discrimination that PLHIV's have to endure.

Counseling is an essential component in the comprehensive set of interventions, which minimize and reduce the risk of transmitting the HIV disease and promote wellbeing. It is crucial to identify biases and prejudices when counseling PLHIV's. They should be guided and educated on the benefits of a healthy lifestyle. It is important to respect the rights of PLHIV's to remain sexually active and to support them and their partners in preventing further HIV transmission.

For PLHIV's living in a third world country such as the Philippines, health services to monitor the physical and emotional wellness of PLHIV's are essential. Antiretroviral drugs should be subsidized, considering the economic status of the individual with HIV, to make ART readily available.

It is wise to remember that prevention is always better than cure. People should always act with extra care and precaution in having sexual relations with a partner positive or negative for HIV. Education is imperative in the HIV awareness and prevention. 


\section{REFERENCES}

American Congress of Obstetricians and Gynecologists (ACOG). (2016). HIV/AIDS resource guide - advocacy. Retrieved from http://www.acog.org/About-ACOG/ACOG-Departments/Health-Care-for-Underserved-Women/HIV-AIDS-Resource-Guide---Advocacy

AIDS.gov. (2015a). Alternative therapy. Retrieved from https://www.aids.gov/hiv-aids-basics/just-diagnosedwith-hiv-aids/treatment-options/alternative-therapy/index.html

American Psychiatric Association (APA). (2013). Use of the manual. In Diagnostic and statistical manual of mental disorders, 5th ed. (DSM-5). doi:10.1176/appi.books.9780890425596

Ardales, V. B. (2008). Basic concepts and methods in research (3rd edition). Iloilo City: Concerns, Inc.

Canoy, N. A. \& Ofreneo, M. A. (2011). Becoming and being HIV-positive: The subjective experience of young Filipino gay men living with HIV. Philippine Journal of Psychology, 45 (2), 147-171. Retrieved from http://ejournals.ph/index.php?journal=PJP\&page=article\&op=view\&path\%5B\%5D=6234\&path\% $5 B \% 5 D=6442$

Centers for Disease Control and Prevention (CDC). (2015). HIV transmission. Retrieved from www.cdc.gov/ hiv/basics/transmission.html

Centers for Disease Control and Prevention (CDC). (2017, March 7). Typhus fevers. Retrieved from https:// www.cdc.gov/typhus/

Crowley, J. S. \& Guni, F. (2004). Background on HIV/AIDS stigma. HIV/AIDS stigma: Theory, reality, and response, 10-15. HIV/AIDS Bureau, Health Resources and Services, U.S. Department of Health and Human Services Administration. Retrieved from https://archive.org/stream/hivaidsstigmatheOOhiva/hivaidsstigmathe00hiva_djvu.txt

Groenewald, T. (2004). A phenomenological research design illustrated. International Journal of Qualitative Methods, 3 (1). Article 4. Retrieved from http://www.ualberta.ca/ iiqm/backissues/3_1/pdf/ groenewald.pdf

Hall, S. K. (2003). A phenomenological investigation into the lives of HIV positive South Africans. Master's Thesis, Psychology Department, University of Zululand, South Africa. Retrieved on December 22, 2015 from http://uzspace.uzulu.ac.za/handle/10530/53

HIV Clinical Resource. (2006). Anxiety disorders in patients with HIV/AIDS. Retrieved from http:// www.hivguidelines.org/clinical-guidelines/hiv-and-mental-health/anxiety-disorders-in-patients-with-hivaids/

HIV Clinical Resource. (2007). Suicidality and violence in patients with HIV/AIDS. Retrieved from http:// www.hivguidelines.org/clinical-guidelines/hiv-and-mental-health/suicidality-and-violence-in-patients-with-hivaids/

HIV Positive Magazine. (2015). Introduction to HIV medications. Retrieved from http://www.hivpositivemagazine.com/meds.html

Kafle, N. P. (2011). Hermeneutic phenomenological research method simplified. Bodhi: An Interdisciplinary Journal, 5 (1), 181-200. Retrieved from http://www.ku.edu.np/bodhi/vol5_no1/11.\%20 Narayan\%20Kafle.\%20Hermeneutic\%20Phenomenological\%20Research\%20Method.pdf

Mahmoudi, M., Dehdari, T., Shojaeezadeh, D., \& Abbasian, L. (2015). Coping With Stress Strategies in HIV-infected Iranian Patients. Retrived from https://www.ncbi.nlm.nih.gov/pubmed/25769759

McQuillen, J. L. (2014). A phenomenological study of aging with HIV/AIDS: In the words of those who really know. Retrieved from http://digitalcommons.unl.edu/dissertations/AAl3666981/

Mohammadpour, A., Yekta, Z. P., Nasrabadi, A. N., Ahmadi, R., \& Mohammadzadeh, A. (2014). Hope and Fear in Living with HIV/AIDS: a Phenomenological Study. Retrieved from http://hayat.tums.ac.ir/ browse.php?a_id=793\&sid=1\&slc_lang=en

Murray, M., Nelson, G., Poland, B., Maticka-Tyndale, E., \& Ferris, L. (2004). Assumptions and values of community health psychology. Retrieved from https://www.researchgate.net/publication/5331739_ Assumptions_and_Values_of_Community_Health_Psychology

Nordqvist, C. (2014). What is a pandemic? What is an epidemic? Retrieved from http://www.medicalnewstoday.com/articles/148945.php 
Pandey, S. \& Kulkarni, B. (2015). Comparative study of stress coping mechanism between police officers and employees of MNC. International Journal of Innovative Research and Studies, 4 (6), 243-285. Retrieved from http://www.ijirs.com/vol4_issue-6/18.pdf

Rodkjaer, L., Sodemann, M., Ostergaard, L., \& Lomborg, K. (2011). Disclosure decisions: HIV-Positive persons coping with disease-related stressors. Qualitative Health Research, 20 (10), 1-11. Retrieved from http://pure.au.dk/portal/files/39701450/Disclosure_decisions.pdf

Roldán, I. (2007). AIDS stigma in the Puerto Rican community: An expression of other stigma phenomenon in Puerto Rican Culture. Interamerican Journal of Psychology, 41(1), 41-48. Retrieved from http:// pepsic.bvsalud.org/pdf/rip/v41n1/v41n1a05.pdf

Rouleau, G., Côté, J., \& Cara, C. (2012). Disclosure experience in a convenience sample of Quebec-born women living with HIV: A phenomenological study [Abstract]. BMC Women's Health, 12(37). doi: 10.1186/1472-6874-12-37.

Sailor, J. L. (2013). A phenomenological study of falling out of romantic love. The Qualitative Report, 18 (Art. 37), 1-22. Retrieved from http://www.nova.edu/ssss/QR/QR18/sailor37.pdf

Simon, M. K. \& Goes, J. (2013). What is phenomenological research? Retrieved on from http://dissertationrecipes.com/wp-content/uploads/2011/04/Phenomenological-Research.pdf

Starks, H. \& Trinidad, S. B. (2007). Choose Your Method: A Comparison of Phenomenology, Discourse Analysis, and Grounded Theory. Qualitative Health Research, 17 (10), 1372-1380. Retrieved from http://www.tree4health.org/distancelearning/sites/www.tree4health.org.distancelearning/files/ readings/Starks_Trinidad_choosing_qual_approach_article.pdf

Tuffelmire, D. (2015). The advantages of narrative writing. In Synonym.com. Retrieved from http://classroom.synonym.com/advantages-narrative-writing-1248.html

Vila, A. C. (2015). FULL TEXT: Miss Universe 2015 Q\&A with top 5 contestants. The Philippine Star. Retrieved from http://www.philstar.com/entertainment/2015/12/21/1535034/full-text-miss-universe2015-qa-top-5-contestants

Yeji, F., Klipstein-Grobusch, K., Newell, M., Hirschhorn, L. R., Hosegood, V., \& Bärnighausen, T. (2014). Are social support and HIV coping strategies associated with lower depression in adults on antiretroviral treatment? Evidence from rural KwaZulu-Natal, South Africa. AIDS Care: Psychological and Socio-medical Aspects of AIDS/HIV. DOI:10.1080/09540121.2014.931561. 